JAKuB CZOPEK

\title{
Opowieść transmedialna jako przykład kreacyjnych możliwości fandomu
}

\begin{abstract}
Jakub Czopek, Opowieść transmedialna jako przykład kreacyjnych możliwości fandomu [Transmedia story as an example of creative possibilities of fandom]. Interdyscyplinarne Konteksty Pedagogiki Specjalnej, nr 23, Poznań 2018. Pp. 191-202. Adam Mickiewicz University Press. ISSN 2300-391X. DOI: https://doi.org/10. 14746/ikps.2018.23.11
\end{abstract}

The subject of the article is the creative activity of fan communities (fandom), with particular emphasis on the transmedia storytelling, i.e. the story told simultaneously within various media. The development of the Internet in the Web 2.0 formula has opened a number of possibilities for the creation of fandoms centered around a particular series, movies, books or games. The main manifestations of the activity of these groups can be reduced on the one hand to analyzing and commenting on a given text of culture, and on the other hand, to develop it, by adding new stories, often using other medium than the one originally used.

KEY WORDS: fandom, transmedia storytelling, culture of remix, creativity

Powstanie internetu i udostępnienie go do celów komercyjnych rozrastającej się z roku na roku liczbie użytkowników stanowi bezapelacyjnie milowy krok w rozwoju kultury w ostatnich dziesięcioleciach. Interaktywność Web 2.0 otworzyła przed zwykłymi odbiorcami mediów nowe możliwości. Nie musieli już być skazani na bierny dostęp do treści przekazywanych im przez zinstytucjonalizowanych nadawców. Podstawą i sensem istnienia mediów spo- 
łecznościowych takich jak Youtube czy Facebook jest przede wszystkim twórczość zwykłych użytkowników, prezentowana na tych portalach $\mathrm{w}$ formie filmów, zdjęć, komentarzy czy własnych przemyśleń. Możliwość kontaktu z innymi, budowania relacji skupionych wokół konkretnego tematu (książki, filmu, typu muzyki itp.) pozwoliła entuzjastom każdego przejawu kultury na znalezienie się (przynajmniej $\mathrm{w}$ teorii) $\mathrm{w}$ gąszczu milionów internautów i wspólne oddawanie się swoim pasjom. Web 2.0 daje zdecydowanie więcej możliwości niż "stara sieć" Web 1.0. Możliwa do zaistnienia stała się tym samym idea prosumpcji, o której kilkadziesiąt lat temu pisał już Alvin Toffler1. Klient odbiorca nowego typu prosument - łączy w sobie cechy charakterystyczne dla konsumenta i producenta. $Z$ jednej strony jest takim samym odbiorcą treści medialnych, które odbiera i „konsumuje” dzięki stale rozwijającym się środkom masowego komunikowania. $Z$ drugiej natomiast ma możliwość produkcji, a więc tworzenia własnych treści. Ta twórcza działalność prosumenta wymaga rzecz jasna większych kompetencji niż bierna konsumpcja. Składają się na nie przede wszystkim umiejętności techniczne i informatyczne związane z obsługą urządzeń elektronicznych, a także odpowiedni poziom wiedzy na temat sieci i miejsc, w których własne "produkty” mogą być upublicznione.

Coraz wyraźniejszych kształtów nabiera wobec tego kultura uczestnictwa, którą Henry Jenkins opisywał jako kontrastową wobec starszych przekonań o pasywnej postawie medialnej publiczności ${ }^{2}$. W kulturze uczestnictwa to konsumenci (oraz ich szczególna odmiana - fani) są zapraszani do aktywnego uczestniczenia w tworzeniu i redystrybucji nowych treści ${ }^{3}$. Zatarte zostają tym samym

${ }^{1}$ A. Toffler, Trzecia fala, przeł. E. Woydyłło, M. Kłobukowski, Wydawnictwo Kurpisz SA, Poznań 2006, s. 305-329. Por. T. Szymusiak, Prosument - Prosumpcja Prosumeryzm: Ekonomiczne oraz społeczne korzyści prosumpcji na przykładzie Polski oraz Niemiec (podejście naukowe), Wydawnictwo Bezkresy Wiedzy, Saarbrücken 2015.

${ }^{2} \mathrm{H}$. Jenkins, Kultura konwergencji. Zderzenie starych $i$ nowych mediów, przeł. M. Bernatowicz, M. Filiciak, Wydawnictwa Akademickie i Profesjonalne, Warszawa 2007, s. 9.

${ }^{3}$ Ibidem, s. 257. 
tradycyjne role. Internauta staje się nie tylko odbiorcą, ale i nadawcą. Profesjonalny twórca może realizować się z pozycji admiratora tekstów kultury, a jego miejsce zajmie amator. Takie podejście do charakteru kultury początku XXI w. znalazło oczywiście krytyków. Andrew Keen pisał wprost o kulcie amatora4, który poprzez postawienie przeciętnego odbiorcy w roli eksperta prowadzi do degradacji i w dalszej kolejności do destrukcji wartości kultury. O ile można się zgodzić z tezą, jakoby fetyszyzowanie twórczości oddolnej i stawianie jej na piedestale $\mathrm{w}$ dłuższej perspektywie może prowadzić do stosunkowo negatywnych efektów, to jednak całkowite demonizowanie takich wytworów kultury wydaje się nieuprawnione. Poszerzanie kompetencji medialnych i komunikacyjnych użytkowników, a także związany z tym potencjał budowania relacji i społeczeństwa zaangażowanego w tworzenie i korzystanie $\mathrm{z}$ kultury, są wartościami, które powinny być pielęgnowane i rozwijane.

Inną ważną konsekwencją rozwoju Web 2.0, pośrednio związaną z kulturą uczestnictwa, jest tzw. inteligencja zbiorowa (ang. collective inteligence), rozumiana jako swego rodzaju „wartość dodana” do wspólnych działań użytkowników sieci. Opisując ten fenomen Pierre Lévy sugeruje, że właśnie z tej współpracy równorzędnych podmiotów narodzi się nowa forma kultury - obieg ekspresji, gdzie każdy z zaangażowanych użytkowników będzie jednocześnie odpowiedzialny za tworzenie nowych treści i podtrzymywanie aktywności innych użytkowników, a „rozróżnienie pomiędzy autorami i czytelnikami, producentami i widzami, twórcami i interpretatorami zatrze się" 5 .

To właśnie Web 2.0 pozwolił na dynamiczny rozwój społeczności fanów - fandomów. Istniały one rzecz jasna wcześniej, ale dopiero internet jako główne medium McLuhanowskiej "globalnej wioski” pozwolił im na „odnalezienie się” w przestrzeni. Ważne w tym

${ }^{4}$ A. Keen, Kult amatora: jak internet niszczy kulturę, tłum. M. Bernatowicz, K. Topolska-Ghariani, Wydawnictwa Akademickie i Profesjonalne, Warszawa 2007.

${ }^{5}$ P. Lévy, Collective inteligence: Mankind's Emerging World in Cyberspace, Perseus Books, Cambridge 1997, s. 20. 
miejscu staje się wskazanie cech dystynktywnych, które pozwolą na odróżnienie zwykłego odbiorcy od fana. Wszak nie każdy, komu podoba się dany tekst kultury, zostaje fanem. Zdaniem Małgorzaty Lisowskiej-Magdziarz "fan to ktoś, kto aktywnie wyraża upodobanie, uznanie, zachwyt dla wybranej książki, komiksu, filmu, programu telewizyjnego, gry czy innego dzieła lub produktu przemysłu kultury"6. Dla fana (jak i dla całego fandomu) charakterystyczny jest głębszy związek z tekstem, rzutujący zarówno na psychologiczny stosunek do niego, jak i na nastawienie i preferencje odbiorcze. Zdaniem Pearson „fani włączają tekst kultury jako część swojej tożsamości, często posuwając się do budowania sieci społecznych na bazie wspólnych upodobań"7. Waga przykładana do tej części tożsamości i budowanych na jej podstawie sieci społecznych wyraźnie oddziela fana od zwykłego entuzjasty. Te sieci społeczne to właśnie fandomy, skupiające fanów konkretnych wytworów kultury. Wytwory te stają się tym samym „atraktorami kulturowymi”, które przyciągają różne społeczności i stanowią dla nich punkt zbieżny. Wiąże się z tym funkcja "aktywatora kulturowego" - stymulatora skłaniającego do kolejnych odszyfrowań znaczenia danego wytworu oraz opracowywania własnych nawiązań i kontekstów jego odczytywania ${ }^{8}$. Realnych kształtów nabiera tym samym kultura remiksu, której nadejście postulował Lawrence Lessig9 . Cytowanie, samplowanie czy remiksowanie fragmentów istniejących tekstów kultury przez zwykłych użytkowników i wytwarzanie na ich podstawie czegoś nowego ma zdaniem tego autora przyczyniać się do bardziej demokratycznego rozwoju kultury. Ważna jest w tym rola środków technicznych umożliwiających łączenie (przede wszystkim

${ }^{6}$ M. Lisowska-Magdziarz, Fandom dla początkujących. Część I. Społeczność i wiedza, Instytut Dziennikarstwa, Mediów i Komunikacji Społecznej UJ, Kraków 2017, s. 15.

7 R. Pearson, Bachies, Bardies, Trekkies, and Sherlockians, [w:] Fandom. Identities and Communities in A Mediated World, red. J. Gray, C. Sandvoss, C. Lee Harrington, New York University Press, New York 2007, s. 98-109.

8 P. Lévy, op. cit., s. 23-24.

${ }^{9}$ L. Lessig, Remiks. Aby sztuka i biznes rozkwitaty w hybrydowej gospodarce, Wydawnictwa Akademickie i Profesjonalne, Warszawa 2009, s. 60-89. 
w formatach cyfrowych) tych fragmentów oraz umiejętność ich obsługi przez użytkowników.

Działalność fandomu sprowadza się de facto do dwóch typów aktywności ${ }^{10}$. Pierwszy z nich nazwać możemy analitycznym lub afirmatywnym. Sprowadza się on do opisu i analizy danego tekstu kultury (kolejnego odcinka serialu, nowego tomu książkowej sagi itp.). Fani analizują poszczególne sceny, nowych bohaterów, ich zachowanie, zgodność i spójność z poprzednimi częściami cyklu. Innymi słowy - wgłębiają się w tekst, poznają go na wylot, komentują, recenzują i dyskutują o nim, by w końcu stać się ekspertami $\mathrm{w}$ tej (stosunkowo wąskiej) dziedzinie. Drugi typ aktywności nazwać możemy twórczym. Rzecz jasna nie stoi on w opozycji do typu pierwszego, jest raczej jego praktycznym wykorzystaniem. Polega przede wszystkim na rozwijaniu wątków z ulubionego serialu lub książki w autorskich "dalszych ciągach”, alternatywnych zakończeniach czy historiach toczących się na marginesie opowieści z głównego medium. Innymi słowy typ twórczy można nazwać kolejnym stopniem wtajemniczenia, jako że niemożliwe jest twórcze wykorzystanie tematów i bohaterów charakterystycznych dla danego tekstu kultury bez jego gruntownej znajomości. Nieco szerszego opisu działalności współczesnych fanów dostarcza M. Lisowska-Magdziarz, wyróżniając jej siedem potencjalnych obszarów: wielokrotna recepcja wybranego tekstu kultury (zarówno zbiorowa, jak i indywidualna), interpretacja i analiza tego tekstu, uzupełnianie, porządkowanie i wymiana wiedzy z nim związanej, twórczość artystyczna inspirowana tym tekstem, budowanie i podtrzymywanie społeczności wokół tekstu kultury, złożonej z osób o identycznych upodobaniach i takim samym sposobie odbioru, działania organizacyjne i budowa infrastruktury na rzecz tej społeczności (w postaci choćby zakładania blogów, stron na Facebooku, organizacji zlotów fanów), autoobserwacja i autoanaliza11.

10 Por. K. Hellekson, K. Buse, The Fan Fiction Studies Reader, University of Iowa Press, Iowa City 2014, s. 3-5.

11 M. Lisowska-Magdziarz, op. cit., s. 16. 
Głównym przejawem aktywności fanów, na którym chciałbym się skupić w niniejszym tekście, jest opowiadanie transmedialne (występujący również jako opowieść transmedialna) - twór dość mocno zakorzeniony w kulturze fanowskiej, ale niezbyt znany poza nią. W literaturze przedmiotu termin ten pojawił się po raz pierwszy w „Kulturze konwergencji” H. Jenkinsa, wydanej w oryginale w 2006 r. (wydanie polskie - 2007)12. Ważne jest rozróżnienie opowiadania rozumianego jako czynność od opowiadania jako gotowego tekstu będącego wynikiem tej czynności. Stąd też obecność $\mathrm{w}$ literaturze angielskiej terminu transmedia storytelling na opisanie tego zjawiska, podkreślającego sam akt tworzenia. Jedną z pełniejszych definicji na polskim gruncie zaproponowała Katarzyna Kopecka-Piech w Leksykonie konwergencji mediów: opowiadanie transmedialne jest opowiadaniem

w poprzek wielu platform medialnych, opartym na rozlicznych komponentach, przynoszących $\mathrm{w}$ efekcie progres narracyjny. [...] W odróżnieniu od wieloplatformowości transmedialność nie opiera się tylko i wyłącznie na zastosowaniu zróżnicowanych mediów, lecz również na utworzeniu między nimi relacji, które skutkują nową, często nielinearną strukturą opowiadania. Transmedia nie oznaczają opowiadania tej samej historii na różnych platformach, ale przekazywanie różnych informacji na temat tego samego świata przedstawionego. Opowiadanie transmedialne angażuje docelowo odbiorcę do zróżnicowanych aktywności, dzięki którym kolekcjonuje on poszczególne komponenty, by dotrzeć do całokształtu opowiadania. Na paletę medialną $\mathrm{w}$ takim przypadku może się składać np. serial, jako komponent zasadniczy, oraz towarzyszące mu: strona internetowa, książka, gra komputerowa czy film pełnometrażowy ${ }^{13}$.

Jednym z pierwszych przykładów opowieści tego typu w mediach głównego nurtu była historia Laury Palmer i miasteczka Twin Peaks. Wkrótce po premierze serialu w reż. Davida Lyncha (pierw-

12 H. Jenkins, op. cit., s. 95-96 i 260.

${ }^{13}$ K. Kopecka-Piech, Leksykon konwergencji mediów, Wydawnictwo Universitas, Kraków 2015, s. 40-41. 
szy odcinek wyemitowano w kwietniu 1990 r.) na rynku pojawiła się książka The Secret Diary of Laura Palmer (Sekretny dziennik Laury Palmer, polskie wydanie dopiero w 2017 r.). Jej autorką miała być dziewczyna, której morderstwo stanowi punkt wyjścia fabuły serialu, a prowadzona w pierwszej osobie narracja rzucać miała nowe światło na życie bohaterki. W rzeczywistości książkę napisała Jennifer Lynch, córka reżysera serialu. Historia znana z telewizja przeszła tym samym do medium drukowanego, nie w formie klasycznej książkowej adaptacji, ale raczej rozwinięcia i uzupełnienia pewnych wątków. Taką samą rolę odegrała animowana seria "The Animatrix" wobec trzyczęściowego cyklu filmowego "Matrix” autorstwa braci Wachowskich.

Głównym medium wykorzystywanym przez fanów są opowiadania typu fan fiction, zwane fanfikami. Rzecz jasna forma prozatorska jest najłatwiejszą do zastosowania. Nie wymaga obsługi skomplikowanych środków technicznych, jak kamera filmowa czy komputerowe programy graficzne. Jednym z największych portali prezentujących twórczość fanowską tego typu jest Archive of Our Own ${ }^{14}$ (Nasze własne archiwum). Największym polskim serwisem tego typu jest FanFiction.pl ${ }^{15}$. Fani realizują się także w formach innych niż pisane. Na portalu Deviantart ${ }^{16}$ znaleźć można twórczość artystyczną - ilustracje, kolaże, komiksy, a także klipy wideo będące kolażami scen z filmów lub seriali.

Najlepsze warunki do rozwoju opowieści transmedialnej pojawiają się w kontekście rozbudowanych uniwersów. Im więcej bohaterów, także tych drugo- i trzecioplanowych, tym więcej możliwości dla rozwoju fanowskiej twórczości. Co więcej, bohaterów nie ograniczają już ramy świata przedstawionego w jednym medium. Mogą oni swobodnie przenikać między tymi światami i tylko od wyobraźni autora zależy, gdzie trafią. $W$ momencie, gdy fani przejmują od zinstytucjonalizowanych nadawców medialnych pióro, którym

\footnotetext{
14 https:/ / archiveofourown.org [dostęp: 27.07.2018].

15 http:/ / www.fanfiction.pl [dostęp: 27.07.2018].

16 https://www.deviantart.com [dostęp: 27.07.2018].
} 
pisze się historię danego bohatera, jego historia z zamkniętej ( $w$ filmie lub książce) całości staje się w zasadzie niekończącą się opowieścią. W momencie, gdy uniwersum danego bohatera jakimś cudem ulegnie pełnemu wyeksploatowaniu, nic nie stoi na przeszkodzie skrzyżowania jego losów z historią zupełnie innych postaci, z całkowicie odmiennych światów, $\mathrm{w}$ formie tzw. crossover. Jednym $\mathrm{z}$ najwyżej ocenianych opowiadań $\mathrm{w}$ tej kategorii na archiveofourown.org jest historia, w której bohaterowie "Star Wars" trafiają do szkoły magii w Hogwarcie, znanej z cyklu o Harrym Potterze ${ }^{17}$. Sam portal skupia ponad 1,5 miliona użytkowników, którzy umieścili na nim ponad 4 mln tekstów, tworzących blisko 30 tys. różnych fandomów. Najpopularniejsze związane są m.in. ze światem „Star Wars”, Harrym Potterem, Sherlockiem Holmesem i światem superbohaterów Marvela. Coś dla siebie mogą znaleźć także entuzjaści... Trylogii Henryka Sienkiewicza - np. opowiadania eksplorujące wątek zakazanej miłości pomiędzy Janem Skrzetuskim a... Bohunem ${ }^{18}$.

Pojawia się tu ważny rys twórczości fanowskiej - przekraczanie granic, także tych związanych z erotyką czy przemocą. To, co nie ma prawa ${ }^{19}$ pojawić się $\mathrm{w}$ mainstreamowych mediach i w oficjalnych wytworach kultury związanych $\mathrm{z}$ danym bohaterem czy uniwersum, może znaleźć swoje miejsce w świecie fandomu. Stąd obecność w opowiadaniach różnego rodzaju związków pomiędzy bohatera$\mathrm{mi}$, nierzadko z uwypuklonymi wątkami erotycznymi, a także mocniejsze akcentowanie przemocy, która w powszechnie dostępnych produktach kulturowych jest tonowana.

John Fiske w Television Culture wprowadził podział tekstów kultury na trzy poziomy. Poziom pierwszy to główny tekst, przekaz, do którego mogą odnieść się odbiorcy (np. film lub serial). Teksty

${ }_{17}$ Nocturnal Studies and other Peculiar Magic, https://archiveofourown.org/ works/8694634/chapters/19935013 [dostęp: 27.07.2018].

18 Ogniem i Sercem, https://archiveofourown.org/works/13219485/chapters/ 30238233 [dostęp: 27.07.2018].

${ }^{19}$ Zarówno przez swój niemoralny, obrazoburczy charakter, jak i przez fakt skierowania przygód danego bohatera do małoletniego odbiorcy. 
drugiego poziomu to wszystko to, co odnosi się do tekstu poziomu pierwszego (a więc zarówno fachowe recenzje filmu, jak i dyskusje jego odbiorców $\mathrm{w}$ internecie ${ }^{20}$ ). Poziom trzeci tworzony jest natomiast przez odbiorcę z połączenia tekstów z dwóch pozostałych poziomów. Właśnie tutaj sytuuje się wszelkiego rodzaju fan fiction, stanowiąc najszerszą formę przetworzenia i reinterpretacji tekstu źródłowego ${ }^{21}$. Ta reinterpretacja jest swoistym sprzężeniem zwrotnym, które trafia do twórców oryginalnego dzieła, dając im informację o sposobie jego odczytania przez fanów i ich oczekiwaniach.

Narracje transmedialne są rzecz jasna wykorzystywane także przez przedsiębiorstwa medialne. Globalne marki pokroju komiksowych superbohaterów stopniowo "kolonizują" kolejne media. Historie, które kiedyś wypełniały karty komiksów, dzisiaj rozwijane są w filmach (tak animowanych, jak i fabularnych), serialach i grach komputerowych. Uniwersum „Gwiezdnych wojen” jest już dostępne w każdej medialnej formie. Saga o wiedźminie, zapoczątkowana przez cykl książek Andrzeja Sapkowskiego, została rozwinięta $\mathrm{w}$ postaci gier komputerowych wydawanych przez studio CD Projekt, 13-odcinkowy serial telewizyjny i film fabularny z $2001 \mathrm{r}$. w reż. Marka Brodzkiego (prod. Heritage Films), a w 2020 r. uzupełnić ją ma kolejny serial, tym razem produkowany przez amerykańską platformę Netflix ${ }^{22}$. Zsyła to na odbiorcę przysłowiową "klęskę urodzaju”. Do poznania historii z każdego medium konieczny jest czas i rzecz jasna dostęp (rozumiany również jako ograniczenie ekonomiczne) do tegoż medium. Ważnym aspektem transmedialności staje się tym samym samowystarczalność. Każdy wątek opowiadanej historii powinien być zamkniętą całością, tzn.

${ }^{20}$ Fiske opublikował swoją książkę w 1987 r., a więc w czasie, kiedy nikt jeszcze nie słyszał o powszechnie dostępnym internecie, mediach społecznościowych i dyskusjach prowadzonych w sieci. Niewątpliwie jednak przedstawione tam tezy odnieść można z powodzeniem także do pewnych aspektów funkcjonowania internetu.

21 J. Fiske, Television culture, Routledge, New York 2011, s. 123-125.

22 T. Gardziński, Twórcy Wiedźmina od Netfliksa zaczynaja szukać aktorów. Kto zagra Geralta? https://www.spidersweb.pl/rozrywka/2018/05/23/wiedzmin-netflixgeralt-aktor [dostęp: 26.07.2018]. 
nie powinna być konieczna znajomość filmu do tego, by cieszyć się grą komputerową i odwrotnie. Oczywiście znajomość całości opowieści czyni doświadczenie bogatszym i w pewnym sensie pełnym, ale nie powinien być to warunek konieczny do korzystania $\mathrm{z}$ historii opowiadanych w różnych mediach.

W tym miejscu może pojawić się sceptyczna reakcja czytelnika niniejszego artykułu - czy taka „pisanina” osób nieznanych szerszej publiczności zasługuje na zainteresowanie? Czy eksploatowanie znanych bohaterów i umieszczanie ich w coraz to nowych sytuacjach i kontekstach ma sens? Z całą pewnością $\mathrm{w}$ tych milionach wytworów kultury fanowskiej znajdą się takie, których poziom językowy będzie niedostateczny, a ich autorom daleko będzie do literackiego Nobla. Niewątpliwie jednak każda działalność kreacyjna zasługuje na uwagę, zwłaszcza w przypadku młodego człowieka. Zachęcenie do zainteresowania się literaturą, rozwijanie wyobraźni, szlifowanie warsztatu pisarskiego (lub graficznego w przypadku ilustracji czy komiksów), włączenie w obieg kulturowy - to tylko niektóre korzyści płynące z wykorzystania tego typu tekstów kultury.

Warto poruszyć jeszcze jeden wątek, będący niejako drugą stroną tej monety. Produkcja własnych treści medialnych przez użytkowników i upublicznianie ich w sieci powinna być z całą pewnością uznana za zjawisko pozytywne. Jednak jak dowodzą badania Jen Schradie ${ }^{23}$, z tym zjawiskiem wiąże się tzw. „cyfrowa luka produkcyjna”. Autorka starała się odpowiedzieć na pytanie „kto odpowiada za treści umieszczane w sieci?” i tym samym określić profil charakterystyczny dla typowego kreatora nowych treści. Efektem tych badań było określenie m.in. faktu istnienia wyraźnego podziału między użytkownikami aktywnymi - twórczymi oraz biernymi skupiającymi się tylko na odbiorze treści, który biegł wzdłuż ich poziomu wykształcenia i stopnia dochodów w rodzinie. Innymi słowy: im wyższy status materialny i poziom wykształcenia, tym większe prawdopodobieństwo, że dana osoba aktywnie współtwo-

23 J. Schradie, The digital production gap: The digital divide and Web 2.0 collide, "Poetics" 2011, nr 39, s. 145-168. 
rzy zasoby internetowe. Ta „cyfrowa luka produkcyjna” stanowi $\mathrm{w}$ pewnym sensie kolejny szczebel cyfrowego podziału (ang. digital divide).

Jednak nawet jeżeli twórczość użytkowników sieci związana jest z kilkoma czy kilkunastoma procentami z nich, to nie zmienia to faktu, że mamy obecnie do czynienia z bardzo prężnie rozwijającą się gałęzią internetowej kreatywności. O ważności tego fenomenu świadczyć może prężnie rozwijająca się gałąź fan studies, która także w Polsce doczekała się własnych publikacji ${ }^{24}$.

\section{Bibliografia}

Fiske J., Television culture, Routledge, New York 2011.

Gardziński T., Twórcy Wiedźmina od Netfliksa zaczynają szukać aktorów. Kto zagra Geralta? https://www.spidersweb.pl/rozrywka/2018/05/23/wiedzmin-netflixgeralt-aktor [dostęp: 26.07.2018].

Hellekson K., Buse K., The Fan Fiction Studies Reader, University of Iowa Press, Iowa 2014.

Jenkins H., Kultura konwergencji. Zderzenie starych i nowych mediów, przeł. M. Bernatowicz, M. Filiciak, Wydawnictwa Akademickie i Profesjonalne, Warszawa 2007.

Keen A., Kult amatora: jak internet niszczy kulture, tłum. M. Bernatowicz, K. TopolskaGhariani, Wydawnictwa Akademickie i Profesjonalne, Warszawa 2007.

Kopecka-Piech K., Leksykon konwergencji mediów, Wydawnictwo Universitas, Kraków 2015.

Lessig L., Remiks. Aby sztuka i biznes rozkwitaty w hybrydowej gospodarce, Wydawnictwa Akademickie i Profesjonalne, Warszawa 2009.

Lévy P., Collective inteligence: Mankind's Emerging World in Cyberspace, Perseus Books, Cambridge 1997.

Lisowska-Magdziarz M., Fandom dla początkujących. Część I. Społeczność $i$ wiedza, Instytut Dziennikarstwa, Mediów i Komunikacji Społecznej UJ, Kraków 2017.

Lisowska-Magdziarz M., Fandom dla początkujących. Część II. Tożsamość i twórczość, Instytut Dziennikarstwa, Mediów i Komunikacji Społecznej UJ, Kraków 2018.

24 Por.: M. Lisowska-Magdziarz, Fandom dla początkujących. Część I. Społeczność i wiedza, Instytut Dziennikarstwa, Mediów i Komunikacji Społecznej UJ, Kraków 2017; M. Lisowska-Magdziarz, Fandom dla początkujacych. Część II. Tożsamość i twórczość, Instytut Dziennikarstwa, Mediów i Komunikacji Społecznej UJ, Kraków 2018. 
Pearson R., Bachies, Bardies, Trekkies, and Sherlockians, [w:] Fandom. Identities and Communities in A Mediated World, red. Gray J., Sandvoss C., Lee Harrington C., New York University Press, New York 2007.

Schradie J., The digital production gap: The digital divide and Web 2.0 collide, "Poetics" 2011, nr 39, s. 145-168.

Szymusiak T., Prosument - Prosumpcja - Prosumeryzm: Ekonomiczne oraz spoteczne korzyści prosumpcji na przykładzie Polski oraz Niemiec (podejście naukowe), Wydawnictwo Bezkresy Wiedzy, Saarbrücken 2015.

Toffler A., Trzecia fala, przeł. E. Woydyłło, M. Kłobukowski, Wydawnictwo Kurpisz S.A., Poznań 2006.

\section{Strony internetowe}

https://archiveofourown.org/

https://archiveofourown.org/works/8694634/chapters/19935013

https://archiveofourown.org/works/13219485/chapters/30238233

https://www.deviantart.com/

http://www.fanfiction.pl/ 